\title{
Research Paper: Physical Activity Among Iranian Former Sportsmen and Athletes as Possible Evidence for Continuity Theory of Aging
}

Salman Naderyan $^{1}$ (D), Robab Sahaf ${ }^{2}$ (D), Ahmad Ali Akbari Kamrani ${ }^{*}$ (D), Yadollah Abolfathi Momtaz ${ }^{2}$ (D), Hossein Ghasemzadeh ${ }^{1}$ (D), Shahab Papi ${ }^{1}$ (iD

1 Department of Ageing, University of Social Welfare and Rehabilitation Sciences, Tehran, Iran.

2. Department of Ageing, Research Center on Ageing, University of Social Welfare and Rehabilitation Sciences, Tehran, Iran.

\begin{tabular}{|c|c|}
\hline $\begin{array}{l}\text { Use your device to scan } \\
\text { and read the article online }\end{array}$ & Citation Naderyan S, Sahaf R, Ali Akbari Kamrani A, Abolfathi Momtaz Y, Ghasemzadeh H, Papi Sh. Physical Activity \\
\hline 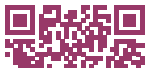 & $\begin{array}{l}\text { Among Iranian Former Sportsmen and Athletes as Possible Evidence for Continuity Theory of Aging. Iranian Rehabilitation } \\
\text { Journal. 2019; } 17(2): 141-148 . \mathrm{http} / / \mathrm{dx} \text {.doi.org/10.32598/irj.17.2.141 }\end{array}$ \\
\hline Prept & doij http://dx.doi.org/10.32598/irj.17.2.141 \\
\hline
\end{tabular}

\section{(i) (3)}

Article info:

Received: 10 Oct 2018

Accepted: 02 Feb 2019

Available Online: 01 June 2019

Keywords:

Physical activity, Athletes, Aging, Older adults

\section{ABSTRACT}

Objectives: Physical activity in late life may be a continuity of activity pattern in the early stages of life. The current study aimed to assess physical activity levels in former Iranian sportsmen and athletes, in 2016.

Methods: This cross-sectional study used convenience sampling method to select 223 former Iranian sportsmen and athletes living in Tehran City, Iran. Informed consents were obtained from all study participants before the study. The short-form Persian version of the International Physical Activity Questionnaire (IPAQ) was used for assessing physical activity. To achieve demographic information, a demographic data Questionnaire was used. For analyzing the obtained data, SPSS was used.

Results: The Mean $\pm \mathrm{SD}$ age of the study participants was $70.81 \pm 8.29$ years. In total, $5.8 \%$, $42 \%$, and $52.9 \%$ of the former athletes had less than 10 minutes of walking, moderate- and vigorous-intensity physical activity, respectively. About $4.9 \%$ of the individuals reported walking on a regular basis and none of them reported daily moderate- and vigorousintensity physical activity. Moreover, $8.5 \%$ of the individuals failed to report walking for at least $10 \mathrm{~min} / \mathrm{d}$. Totally, $43.5 \%$ of the individuals reported no moderate-intensity physical activity and about $56.1 \%$ of them did not participate in any vigorous-intensity physical activities. Furthermore, $31.4,8.5$, and 5.8 of the athletes reported walking, moderate- and vigorous-intensity physical activity for more than 150 minutes per week, respectively. According to the three types of activity defined by the IPAQ, $49 \%$ of the athletes were inactive, $36.3 \%$ were minimally active and about $15 \%$ were physically active. Physical activity decreased with increasing age $(\mathrm{P}<0.01 ; \mathrm{r}=-0.529)$ and had a direct relationship with educational level $(\mathrm{P}<0.01 ; \mathrm{r}=0.278)$.

Discussion: The findings highlight the importance of considering active intervention programs at younger ages to ensure better leisure participation of the elderly, especially in physical activity.

* Corresponding Author:

Robab Sahaf, PhD.

Address: Department of Aging, University of Social Welfare and Rehabilitation Sciences, Tehran, Iran

Tel: +98 (914) 9084706

E-mail:nsali@yahoo.com 


\section{Highlights}

- Physical activity in later life may be a continuation of what was in earlier life.

- Physical activity decreases with increasing age and has a direct relationship with education.

\section{Plain Language Summary}

Physical activity has numerous benefits, especially for older adults. Physical activity in later life may be a continuation of the activity pattern in the early stages of life. In a cross-sectional study, we assessed physical activity in a sample of Iranian former athletes and sportsmen using the International Physical Activity Questionnaire. About 49\% of the former athletes were inactive, $36.3 \%$ were minimally active, and $15 \%$ were physically active. Thus, physical activity has declined with increasing age and has a direct relationship with educational level. The results suggest a pattern of physical activity that continues from earlier stages of life and highlights the importance of considering physical activity interventions at younger ages to ensure later engagement in physical activity.

\section{Introduction}

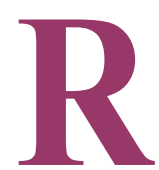

egular participation in physical activity is associated with positive and significant outcomes in older adults. In relation to the burden of noncommunicable diseases, the impact of physical inactivity is similar to the established risk factors such as smoking and obesity [1]. Inactivity is considered as an important risk factor for a number of chronic conditions like cardiovascular diseases [1]. Global estimates suggest that roughly $22 \%$ of ischemic heart disease cases and about $10-16 \%$ of diabetes mellitus cases are attributable to inactivity [2].

In contrast, physical activity has numerous health benefits and a positive effect on the primary and secondary prevention of diseases $[1,3]$. In addition to the young population, physical activity is recommended for older adults with chronic diseases and disabilities [4]. The 2008 Physical Activity Guidelines for Americans affirms that all adults should avoid inactivity; it also states that as the amount of physical activity increases through higher intensity, greater frequency, or longer duration, additional benefits occur [4].

Despite all the benefits correlated with physical activity, studies reported that inactivity is globally prevalent. Epidemiological studies have estimated various prevalence of inactivity in different communities [5-7]. Physical activity tends to decline with age [8], which may accelerate the age-related declines [9]. Sportsmen and athletes perform high levels of physical activity in their professional years. Researchers suggested a pattern of activities which is a combination of current and youth time activities by the elderly. According to the continuity theory of aging, with age, people do not actually change, but become more like how they have always been [10].

This is a psychosocial theory of aging; it assumes that when older adults adapt to changes related to the process of normal aging, their past life will form the basis of their present and future decisions and behaviors. The most ordinary approach in response to aging is retaining the orders of thought, activities, and habits [11]. Accordingly, people with an active lifestyle in their youth, may tend to maintain this pattern of living in their senior years of life. According to Kujala et al. $60 \%$ of former elite athletes maintain an active lifestyle over their adulthood, while merely $17 \%$ of controls do so [12]. Similarly, Minhat et al. reported an important association between the former and current partaking of the elderly in recreational activities [11]. The current study aimed to investigate physical activity status in Iranian former sportsmen and athletes in 2015.

\section{Methods}

The original study sample was supposed to be comprised of 250 individuals. We referred to different federations and collected the primary information and phone numbers of the individuals. Finally, 223 individuals agreed to take part in our study (participation rate $=89.2 \%$ ). In most cases, a face-to-face interview was conducted in different federations, and in some cases, in the subjects' place of residence. Due to the cultural and religious limitations of the Iranian community, the current study was only conducted on males.

The first part of the questionnaire included demographic data on variables such as age, gender, educa- 
tional level, and so on. The Iranian short version of the International Physical Activity Questionnaire (IPAQ) was used as the second part of the questionnaire. Seven items of the IPAQ gather data on walking, moderate- and vigorous-intensity physical activities, and sitting during the previous week, based on time spent for each activity. Based on the IPAQ, moderate physical activities are those resulting in a moderate increase in breath and heart rate and sweating lasting for at least 10 minutes.

This is tantamount to 3-6 Metabolic Equivalent of Tasks (MET) according to the summary of physical activity [13]. Vigorous physical activities are those resulting in vigorous increases in heart and respiration rate and sweating for not less than 10 minutes [13]. The Iranian short version of IPAQ was translated into Persian; it has acceptable reliability and validity for assessing physical activity [14].

We inspected the data, then, entered them into a computer and checked for outliers, based on the guidelines of IPAQ. The obtained data were analyzed using SPSS. Frequencies and percentages of the demographic characteristics and all physical activity levels were computed. The physical activity levels were analyzed in the age groups. Using Spearman's Rho correlation, the associations between the levels of activity, education and age group were explored. Furthermore, MET-min/wk for all physical activity levels was calculated, as follows: Walking $=(3.3 \times$ walking minutes $\times$ walking days $)$; Moderate activity $=(4 \times$ moderate activity minutes $\times$ moderate activity days $)$; Vigorous activity $=(8 \times$ vigorous activity minutes $\times$ vigorous activity days).

In addition, sufficient vigorous activity was calculated based on 3 or more days of vigorous activity of minimum $20 \mathrm{~min} /$ day. Similarly, sufficient moderate and walking activities were calculated based on at least $30 \mathrm{~min} / \mathrm{d}$ of 5 or more days of moderate intensity and walking. We also classified physical activity levels into three groups according to the IPAQ instructions: namely; inactive, minimal activity, and health-enhancing physical activity [13].

\section{Results}

The demographic characteristics of samples are listed in Table 1. The Mean \pm SD age of the study participants was $70.81 \pm 8.29$ years. Most of them aged 60-74 years $(63.7 \%)$. Only $9 \%$ of them had no formal education, most were married (90.6\%), and 87 (39\%) individuals reported various diseases. The individuals' participation in walking, moderate- and vigorous-intensity physical activities based on $\mathrm{d} / \mathrm{wk}$ are presented in Table 2 .
Approximately $5.8 \%$ of the former athletes did not walk for at least 10 minutes at a time on any distinct day of the week. Only $4.9 \%$ of them walked regularly. Moreover, approximately $42 \%$ of former sportsmen did not participate in any moderate-intensity physical activity continuing for at least $10 \mathrm{~min}$. Considering vigorous activity, about $52.9 \%$ of the individuals were never engaged in vigorous-intensity physical activity lasting for at least 10 minutes; none of them reported regular vigorous-intensity physical activity. The distribution of three kinds of physical activities based on $\mathrm{min} / \mathrm{wk}$ is presented in Table 3.

In total, $8.5 \%, 42.6 \%$, and $52.9 \%$ of the former athletes reported no walking, moderate- and vigorous-intensity physical activities, respectively. The percentage of former athletes who walked for 150 min or more per week was $31.4 \%$. Furthermore, the percentage of former athletes who took part in moderate- and vigorousintensity physical activities for 150 min or more per week were $8.5 \%$, and $5.8 \%$, respectively.

Totally, $8.96 \%$ of the former athletes reported sufficient vigorous activity, based on a minimum of 20 $\mathrm{min} / \mathrm{d}$ for at least 3 days per week. Furthermore, $26 \%$ of the athletes reported sufficient moderate-intensity and walking activities, based on 5 or more days a week for at least $30 \mathrm{~min} / \mathrm{d}$.

Table 4 summarizes the physical activity profile of sportsmen, according to three activity levels. Roughly $49 \%$ of former sportsmen were categorized as inactive, whereas approximately $36.3 \%$ and $15 \%$ were in minimally active and active groups, accordingly.

Table 5 and Figure 1 represent the proportions of former sportsmen participating in health-improving physical activities. They were minimally active and inactive, respectively, according to age groups. Health-enhancing physical activity was not reported in individuals older than 70 years. Moderate intensity physical activity was observed in all age groups; individuals older than 80 years were more inactive than other age groups.

We found a significant negative correlation between age and the proportion of adequate vigorous activity ( $\mathrm{r}=$ $0.377 ; \mathrm{P}<0.01$ ). This indicates that younger participants were more likely to engage in sufficient vigorous activity. Age group was conversely related to activity category $(\mathrm{r}=-0.545 ; \mathrm{P}<0.01)$. An important positive relationship was observed between education and physical activity level ( $\mathrm{r}=0.278 ; \mathrm{P}<0.01)$. The least proportion of inactive former athletes was observed in the younger age catego- 
Table 1. The demographic characteristics of study participants $(n=223)$

\begin{tabular}{|c|c|c|c|c|c|c|}
\hline \multicolumn{2}{|c|}{ Variable } & \multirow{2}{*}{$\begin{array}{c}\text { No. } \\
9\end{array}$} & \multirow{2}{*}{$\begin{array}{l}\% \\
4\end{array}$} & \multirow{2}{*}{$\begin{array}{c}\text { Active } \\
4\end{array}$} & \multirow{2}{*}{$\begin{array}{c}\begin{array}{c}\text { Minimally } \\
\text { Active }\end{array} \\
4\end{array}$} & \multirow{2}{*}{$\begin{array}{c}\text { Inactive } \\
1\end{array}$} \\
\hline \multirow{6}{*}{ Age group, $y$} & $>60$ & & & & & \\
\hline & $60-64$ & 39 & 17.5 & 11 & 22 & 6 \\
\hline & $65-69$ & 68 & 30.5 & 18 & 26 & 24 \\
\hline & $70-74$ & 35 & 15.17 & 0 & 13 & 22 \\
\hline & $75-89$ & 43 & 19.33 & 0 & 15 & 28 \\
\hline & $<80$ & 29 & 13 & 0 & 1 & 28 \\
\hline \multirow{6}{*}{ Educational level } & No formal education & 9 & 4 & 0 & 4 & 5 \\
\hline & Elementary & 36 & 16.1 & 1 & 7 & 28 \\
\hline & High elementary & 23 & 10.3 & 3 & 6 & 14 \\
\hline & Diploma and above & 80 & 35.9 & 15 & 31 & 34 \\
\hline & BS & 45 & 20.2 & 7 & 16 & 22 \\
\hline & MA and above & 30 & 13.5 & 7 & 17 & 6 \\
\hline \multirow{5}{*}{ Marital status } & Never married & 1 & 0.4 & 0 & 1 & 0 \\
\hline & Married & 202 & 90.6 & 32 & 78 & 92 \\
\hline & & & & & & \\
\hline & Spouse dead & 17 & 7.6 & 1 & 2 & 14 \\
\hline & Widower & 3 & 1.3 & 0 & 0 & 3 \\
\hline \multirow{5}{*}{$\begin{array}{l}\text { Former professional } \\
\text { activity level }\end{array}$} & None & 4 & 1.8 & 0 & 1 & 3 \\
\hline & City & 41 & 18.4 & 4 & 17 & 20 \\
\hline & Province & 71 & 31.8 & 9 & 28 & 34 \\
\hline & National & 59 & 26.5 & 11 & 19 & 29 \\
\hline & International & 48 & 21.5 & 9 & 16 & 23 \\
\hline
\end{tabular}

ries $(11.1 \%$ and $96.6 \%$ for age groups of $<60$ and $80<$ years, respectively).

\section{Discussion}

There are different methods to analyze physical activity data; however, to our knowledge, there is no consensus on the best method for defining or describing activity level in self-report studies [13]. Numerous studies have reported physical activity features of individuals, using the IPAQ. However, to our knowledge, we reported the physical activity profile of Iranian former sportsmen and athletes using the IPAQ, for the first time. More pre- cisely, it is the first time that these honorable individuals are under focus. The main finding of our study is that not many former sportsmen were sufficiently vigorously active. However, approximately one-fourth of the individuals were sufficiently moderately active. In addition, inactivity prevalence rate among former sportsmen was $48.9 \%$; while, the relative number of people achieving supposed health-promoting physical activity level was about $14.8 \%$.

In a previous survey in Isfahan, the prevalence of inactivity was estimated to be $86.3 \%$ [15]. Studies reporting physical activity data based on the IPAQ are scarce. A 
Table 2. Proportions (\%) of three kinds of physical activity for at least $10 \mathrm{~min}$ at a time (days per week)

\begin{tabular}{cccc}
\hline Number of Days Per Week & Walking & Moderate Activity & Vigorous Activity \\
\hline 0 & 8.5 & 41.7 & 52.9 \\
1 & 1.3 & 17 & 26 \\
\hline 2 & 11.2 & 27.4 & 12.1 \\
3 & 33.6 & 12.1 & 5.8 \\
4 & 12.6 & 1.3 & 0.4 \\
5 & 19.3 & 0.4 & 0 \\
6 & 8.5 & 0 & 0 \\
7 & 4.9 & 0 & 100 \\
\hline
\end{tabular}

Iranian Rehabilitation Journal

survey using the short-form of IPAQ among Brazilian adults reported an inactivity prevalence rate of $41.1 \%$ [16]. Our estimate of the inactivity level of athletes is almost consistent with the previous research. Previous studies used disparate tools for assessing physical activity.

Thus, it is difficult to compare inactivity rates around the world, due to different sampling and assessment

Table 3. Proportions (\%) of participants engaging in three kinds of activity based on the number of min/wk

\begin{tabular}{|cccc|}
\hline Number of Min Per Wk & Walking & Moderate Activity & Vigorous Activity \\
\hline 0 & 8.5 & 42.6 & 52.9 \\
$10-30$ & 4.9 & 5.8 & 0.9 \\
$31-60$ & 23.8 & 29.1 & 9.9 \\
$61-149$ & 31.4 & 13.9 & 15.2 \\
$150-299$ & 18.8 & 7.6 & 15.2 \\
$300 \leq$ & 12.6 & 0.9 & 5.8 \\
\hline Total (\%) & 100 & 100 & 100 \\
\hline
\end{tabular}

Table 4. Physical activity profile of the former athletes

Ilranian Rehabilitation Journal

\begin{tabular}{ccc} 
Activity Category & Percentage & Definitions \\
\hline Inactive & 48.9 & Not meeting criteria for minimally active or activ \\
Minimal activity & 36.3 & $\begin{array}{c}\text { Meeting any of the following criteria: (1) } 3 \text { or more days of vigorous activity for at least } \\
\text { 20min/d; or (2) } 5 \text { or more days of moderate activity or walking for at least } 30 \text { min/d; or (3) } \\
5 \text { or more days of any combination of walking, moderate or vigorous-intensity activities } \\
\text { reaching a minimum of at least } 600 \text { MET-min/wk }\end{array}$ \\
Active & 14.8 & $\begin{array}{c}\text { Meeting one of the following criteria: (1) vigorous-intensity activity for at least } 3 \text { days } \\
\text { reaching a minimum of } 1500 \text { MET-min/wk; or (2) } 7 \text { days or more of any combination of } \\
\text { walking, moderate, and vigorous- intensity activities achieving at least 3000 MET-min/wk }\end{array}$ \\
\hline
\end{tabular}


Table 5. The prevalence of different physical activity status in former sportsmen according to age

\begin{tabular}{ccccc}
\hline Age Group, $\mathbf{y}$ & Active & Minimally Active & Inactive & Total (\%) \\
\hline$<60$ & 44.4 & 44.4 & 11.1 & 100 \\
$60-64$ & 28.2 & 56.4 & 15.4 & 100 \\
$65-69$ & 26.5 & 38.2 & 35.3 & 100 \\
$70-74$ & 0 & 37.1 & 62.9 & 100 \\
$75-79$ & 0 & 34.9 & 65.1 & 100 \\
$80 \leq$ & 0 & 3.4 & 96.6 & 100 \\
\hline
\end{tabular}

methods. It is recommended that all healthy adults need moderate-intensity aerobic (endurance) activity for a minimum of 30 min on 5 days per week or vigorousintensity aerobic activity for a minimum of $20 \mathrm{~min}$ on three days a week. However, Behavioral Risk Factors Surveillance System (BRFSS) in the USA revealed that most of the American adults (54\%) were not physically active [17]. In another study from Saudi Arabia, inactivity prevalence was reported to be about $40.6 \%$ [18].

The relatively low prevalence rate of inactivity found in our study, compared to other studies with almost the same age group requires an explanation. Former athletes are a special group who experienced considerable levels of physical activity in their youth; it is expectable that these people maintain their active lifestyle. Studies demonstrated a continuity pattern in currently performed activities by older adults with that of their youth [10].

Minhat et al. reported a significant continuation between the current and former recreational involvement of the elderly in cognitive, social and productive activi- ties. Those elderly involved in leisure activities in youth, were more likely to perform cognitive, social and productive leisure activities [11]. Consistently, Kujala et al. argued that about $60 \%$ of former elite athletes maintain a physically active lifestyle throughout their adulthood, while only $17 \%$ of controls do so [12]. Similarly, considering the relatively low prevalence of inactivity, our study supported the continuity theory of aging.

Our data revealed that $31.4 \%$ of former athletes walked for $\geq 150 \mathrm{~min} / \mathrm{wk}$. Furthermore, $5 \%$ and $8.5 \%$ of them were regular and never walkers, respectively. A study in the USA revealed that $33.7 \%, 45.6 \%$, and $20.7 \%$ of the population were regular, occasional and never walkers, respectively [19].

Regular physical activity can be a good marker of health-related consequences in the later period of life [20]. Additionally, regular physical activity can positively contribute to the primary and secondary prevention of cardiovascular diseases, cancers, hypertension, diabetes, and other chronic conditions [21]. In a follow-up study

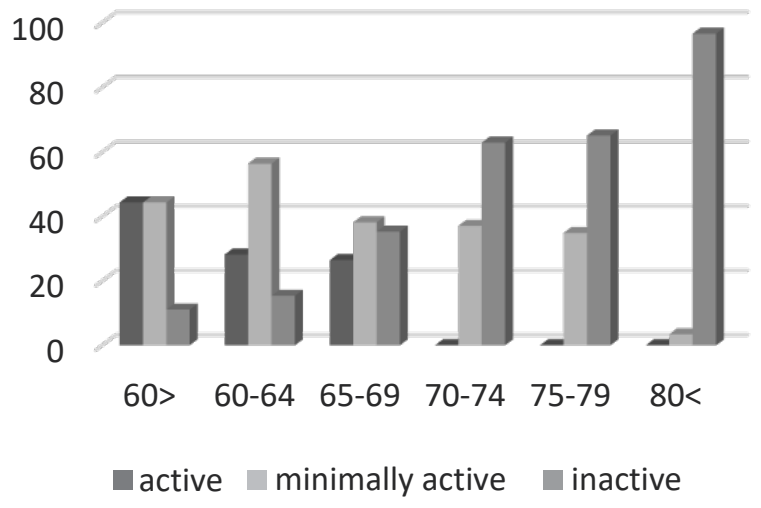


by Zhao et al. walking on a daily base was related to a decreased death risk in older Japanese men [22]. The relatively low numbers of never and regular walker in the present study, with regard to the high mean age of the respondents, can be interpreted as evidence supporting the idea that physical activity tends to decline in old age.

Our study suggests that inactivity increases in older age groups, which has been earlier explored [23]. A study in the USA indicated a steady increase in inactivity with increasing age in both genders [8]. Similarly, A study in Brazil reported a reduction in physical activity practice in leisure time with increasing age [6]. On the other hand, a study on Nigerian civil servants revealed no significant physical activity direction across disparate age groups [24]. However, the above-discussed studies mostly assessed leisure time physical activity; this may partially justify the different results reached, considering the age and inactivity rates.

The finding that physical activity declines with age seems in contrast with the continuity theory of aging. Although some people tend to maintain their physical activity pattern, age-related decline in physical activity seems inevitable. Instead, because of certain obstacles such as retirement, and declined health and physical function, some elderly may pursue another leisure activity to fit their changing circumstances. Strain et al. examined the changes in leisure activities of 380 older adults in Canada over 8 year. They found that watching theater; movies; spectator sports, and travel were least continued over the study period; whilst watching television and reading were mostly continued [25].

The present study found a direct relationship between physical activity and educational level, which is in accordance with other studies. The relationship between physical activity and education is an interesting subject and has been previously investigated $[16,18,26]$. However, the relatively high level of inactivity found in this study, with regard to the high educational attainment of the respondents, can be rather attributable to the lack of attitude, than their knowledge of physical activity.

Our obtained data was based on self-report measures. Therefore, the respondents could have been affected by recall bias. Moreover, due to the cross-sectional nature of our study and the absence of a control group, it was difficult to compare physical activity level and its related factors in the former athletes with that of the normal population. In addition, due to the convenience nature of our sampling method, our study was vulnerable to selection bias and sampling error. Eventfully, we used the short form of IPAQ to assess physical activity; thus, the data of other forms of physical activity might have been disregarded.

\section{Conclusion}

The prevalence of inactivity in former athletes is relatively high, which is a public health concern. However, the high mean age of our study samples must be taken into consideration. Though, certain policies are required to encourage physical activity in older adults. Furthermore, conducting further research with a reasonable sample population and a more specialized Questionnaire is necessary.

\section{Ethical Considerations}

\section{Compliance with ethical guidelines}

The study proposal was approved by the Research Council of the University of Social Welfare and Rehabilitation Sciences in July 2016 (Code: IR.USWR.REC.1395.233). Oral and written consents were obtained from the study participants. Respondents were assured of the confidentiality of their information. The study population consisted of Iranian former athletes and sportsmen.

\section{Funding}

The study was supported by the Research Council of the University of Social Welfare and Rehabilitation Sciences.

\section{Authors' contributions}

Conceptualization: Salman Naderyan, Robab Sahaf, Ahmad Ali Akbari Kamrani; Methodology: Ahmad Ali Akbari Kamrani, Yadollah Abolfathi Momtaz; Investigation: Salman Naderyan, Shahab Papi; Writing original draft: Salman Naderyan, Hossein Ghasemzadeh; Writing-review \& editing: Salman Naderyan, Hossein Ghasemzadeh; and Supervision: Robab Sahaf.

\section{Conflict of interest}

The authors declared no conflict of interest.

\section{References}

[1] Fillit HM, Rockwood K, Young JB. Brocklehurst's textbook of geriatric medicine and gerontology. Amsterdam: Elsevier; 2016. 
[2] World Health Organization. The world health report 2002: Reducing risks, promoting healthy life. Geneva: World Health Organization; 2002.

[3] Beckett MW, Ardern CI, Rotondi MA. A meta-analysis of prospective studies on the role of physical activity and the prevention of Alzheimer's disease in older adults. BMC Geriatrics. 2015; 15:9. [DOI:10.1186/s12877-015-0007-2] [PMID] [PMCID]

[4] Chodzko-Zajko WJ, Proctor DN, Singh MAF, Minson CT, Nigg CR, Salem GJ, et al. Exercise and physical activity for older adults. Medicine \& Science in Sports \& Exercise. 2009; 41(7):1510-30. [DOI:10.1249/MSS.0b013e3181a0c95c] [PMID]

[5] Al-Hazzaa HM. Prevalence of physical inactivity in Saudi Arabia: A brief review. Eastern Mediterranean Health Journal. 2004; 10(4-5):663-70. [PMID]

[6] Dias-da-Costa JS, Hallal PC, Wells JC, Daltoé T, Fuchs SC, Menezes AM, et al. Epidemiology of leisure-time physical activity: A population-based study in Southern Brazil. Cadernos de saude publica. 2005; 21(1):275-82. [DOI:10.1590/S0102311X2005000100030] [PMID]

[7] Hallal PC, Andersen LB, Bull FC, Guthold R, Haskell W, Ekelund U, et al. Global physical activity levels: Surveillance progress, pitfalls, and prospects. The Lancet. 2012; 380(9838):247-57. [DOI:10.1016/S0140-6736(12)60646-1]

[8] Caspersen CJ, Pereira MA, Curran KM. Changes in physical activity patterns in the United States, by sex and crosssectional age. Medicine \& Science in Sports \& Exercise. 2000; 32(9):1601-9. [DOI:10.1097/00005768-200009000-00013]

[9] Paterson DH, Jones GR, Rice CL. Ageing and physical activity: Evidence to develop exercise recommendations for older adults. Applied Physiology, Nutrition, and Metabolism. 2007. 32(S2E):S69-S108. [DOI:10.1139/H07-111]

[10] Agahi N, Ahacic K, Parker MG. Continuity of leisure participation from middle age to old age. The Journals of Gerontology Series B. Sciences. 2006; 61(6):S340-S6. [DOI:10.1093/ geronb/61.6.S340]

[11] Minhat HS, Rahmah M, Khadijah S. Continuity theory of ageing and leisure participation among elderly attending selected health clinics in selangor. International Medical Journal Malaysia. 2013; 12(2):51-8.

[12] Kujala UM, Sarna S, Kaprio J, Koskenvuo M. Hospital care in later life among former world-class Finnish athletes. JAMA. 1996; 276(3):216-20. [DOI:10.1001/jama.276.3.216] [PMID]

[13] Committee IR. Guidelines for data processing and analysis of the International Physical Activity Questionnaire (IPAQ)short and long forms [Internet]. 2005 [Updated 1 November 2005]. Available from: http://www ipaq ki se/scoring pdf. 2005.

[14] Vasheghani-Farahani A, Tahmasbi M, Asheri H, Ashraf H, Nedjat S, Kordi R. The Persian, last 7-day, long form of the International Physical Activity Questionnaire: Translation and validation study. Asian Journal of Sports Medicine. 2011; 2(2):106-16. [DOI:10.5812/asjsm.34781] [PMID] [PMCID]

[15] Eshaghi SR, Shahsanai A, Mellat Ardakani M. Assessment of the physical activity of elderly population of Isfahan, Iran (Persian)]. Journal of Isfahan Medical School. 2011; 29(147):939-46.
[16] Hallal PC, Victora CG, Wells J, Lima RdC. Physical inactivity: Prevalence and associated variables in Brazilian adults. Medicine and Science in Sports and Exercise. 2003; 35(11):1894-900. [DOI:10.1249/01.MSS.0000093615.33774.0E] [PMID]

[17] Macera CA, Jones DA, Yore M, Ham S, Kohl HW, Kimsey Jr C, et al. Prevalence of physical activity, including lifestyle activities among adults-United States, 2000-2001. Morbidity and Mortality Weekly Report. 2003; 52(32):764-9.

[18] Al-Hazzaa HM. Health-enhancing physical activity among Saudi adults using the International Physical Activity Questionnaire (IPAQ). Public Health Nutrition. 2007; 10(1):59-64. [DOI:10.1017/S1368980007184299] [PMID]

[19] Eyler AA, Brownson RC, Bacak SJ, Housemann RA. The epidemiology of walking for physical activity in the United States. Medicine and Science in Sports and Exercise. 2003; 35(9):1529-36 [DOI:10.1249/01.MSS.0000084622.39122.0C] [PMID]

[20] DiPietro L. Physical activity in aging: changes in patterns and their relationship to health and function. The Journals of Gerontology Series A: Biological Sciences and Medical Sciences. 2001; 56(suppl. 2):13-22. [DOI:10.1093/gerona/56. suppl_2.13]

[21] Warburton DE, Nicol CW, Bredin SS. Health benefits of physical activity: The evidence. Canadian Medical Association Journal. 2006; 174(6):801-9. [DOI:10.1503/cmaj.051351] [PMID] [PMCID]

[22] Zhao W, Ukawa S, Kawamura T, Wakai K, Ando M, Tsushita $\mathrm{K}$, et al. Health benefits of daily walking on mortality among younger-elderly men with or without major critical diseases in the new integrated suburban seniority investigation project: A prospective cohort study. Journal of Epidemiology. 2015; 25(10):609-16. [DOI:10.2188/jea.JE20140190] [PMID] [PMCID]

[23] Ham S, Yore M, Fulton J, Kohl III H. Prevalence of no leisure-time physical activity-35 states and the district of Columbia, 1988-2002. Morbidity and Mortality Weekly Report. 2004; 53(4):82-6. [PMID]

[24] Forrest KY, Bunker CH, Kriska AM, Ukoli F, Huston SL, Markovic N. Physical activity and cardiovascular risk factors in a developing population. Medicine and Science in Sports and Exercise. 2001; 33(9):1598-604. [DOI:10.1097/00005768200109000-00025]

[25] Strain LA, Grabusic CC, Searle MS, Dunn NJ. Continuing and ceasing leisure activities in later life: A longitudinal study. The Gerontologist. 2002; 42(2):217-23. [DOI:10.1093/ geront/42.2.217] [PMID]

[26] Salmon J, Owen N, Bauman A, Schmitz MKH, Booth M. Leisure-time, occupational, and household physical activity among professional, skilled, and less-skilled workers and homemakers. Preventive Medicine. 2000; 30(3):191-9. [DOI:10.1006/pmed.1999.0619] [PMID] 